\title{
The influence of integrated information systems on firm financial performance
}

\author{
Ivica Pervan $^{1}$ and Ivana Dropulici ${ }^{1, *}$ \\ ${ }^{1}$ Faculty of Economics, Business and Tourism, University of Split \\ Cvite Fiskovića 5, 21000 Split, Croatia \\ E-mail: 〈\{ivica.pervan, ivana.dropulic\}@efst.hr〉
}

\begin{abstract}
This study investigates the influence of integrated information systems (IIS) features on firm financial performance, more precisely return on asset (ROA). Research results, based on data obtained from 83 firms in 2018, confirmed the positive effect between IIS analytical capabilities on ROA, while IIS scope had negative effect on ROA. Estimated regression model revealed that IIS age and IIS implementation quality did not have any effect over firm financial performance. Findings from the study indicated that firms and IIS vendors should be careful in IIS design phase, taking into account that IIS design incorporates appropriate analytical capabilities required by business processes. Also, scope of selected IIS modules should be rational in order to avoid unnecessary IIS investment costs.
\end{abstract}

Keywords: business performance indicators, Croatia, integrated information systems

Received: September 27, 2020; accepted: December 04, 2020; available online: December 18, 2020

DOI: 10.17535 /crorr.2020.0024

\section{Introduction}

Modern business environment is highly uncertain and complex, which is why firms require more information to make timely business decisions and increase competitiveness. In this context, Enterprise Resource Planning (ERP) systems are emerging which due to the pronounced technological advancements, are recording rapid and intensive development. ERP systems are integrated information systems that administrate and coordinate all the resources, data, and tasks of a firm from one central database [6]. Many research has declared that ERP systems can enhance competitive advantage in the information technology era by reduction of inventory, personnel and costs (IT, procurement, transportation and logistics costs) and by increasing productivity, revenue and profits, visibility of corporate data, flexibility and communications $[17]$.

In contrast to majority of prior researches we are not only concentrated on ERP systems, therefore we use integrated information system (IIS) variable, which comprises ERP and additional specialized applications. In order to clarify use of ERP and IIS terms, here we must point out that term ERP is mainly used in Section 2 when referencing previous research related with ERP, however, the term IIS is used when describing the variable which is used for measurement model in Section 3.

In this research, we study the effects of IIS on the firm business performance. We examine only financial performance indicators, represented by return on assets (ROA). This research contributes to the existing insights in several ways. First, we use comprehensive description of IIS, which comprises ERP and additional specialized applications like consolidation of financial

*Corresponding author. 
statements, managerial reporting, etc. Furthermore, we developed several IIS features (analytical capabilities, age, scope and implementation quality) that may have a significant influence on the firm business performance. Such approach results with improved measurement of IIS variable and with more reliable findings on its influence on firm financial performance. Second, although IIS are expected to result in a better business performance, empirical evidence is unclear $[10,11,14]$. Therefore, in order to fill the gap in existing knowledge, we examine the influence of IIS on the firm business performance. This study represents one of the very rare studies that explores the impact of IIS on firm financial performance in Croatia and in South East European (SEE) countries in general.

Our empirical research is based on survey data drawn from 83 firms in Croatia during 2018. The main findings of our study can be concise as follows. Firstly, we confirmed a significant relationship between two IIS features (IIS analytical capabilities and IIS scope) and return on assets (ROA). Secondly, other IIS features such as IIS age and control variables were insignificant according to evaluated regression model.

The rest of the paper is structured into six sections. In Section 2 we review the literature and in Section 3 we describe the methodology and data. Empirical findings are presented in Section 4 while discussion is in Section 5. Concluding remarks are presented in Section 6.

\section{Literature review}

ERP system represents software solution that covers the entire business of the firm, supports and integrates the work of all functions and integrates all internal and external business processes of the firm [9]. ERP systems implementation represents a firm's largest investment and project as part of a firm's effort to modernize and differentiate itself [12]. Information technologies facilitate key business process enhancements, increasing information quality and decision making [5]. ERP systems investments are expect to increase efficiency and effectiveness and finally financial performance of the firm [6]. Numerous studies have tried to find a positive effect of IT investments, such as ERP systems, on firm performance, however in early research findings have yielded nonsignificant positive association between IT investments and financial performance, a phenomenon that is referred to as the productivity paradox [5]. In recent research, the evidence has been mixed because some research has found certain evidence supporting the theses that ERP systems enable firms to achieve better financial performance [19]. For instance, [6] indicated that the extensive use of formal controls mediates the positive direct influence of ERPs on the non-financial performance of the firm. Some research compare firm performance of adopters and nonadopters of ERP systems results of which indicate that ERP firm' performance was relatively unchanged from pre to post adoption, while non-ERP firm' performance significantly dropped over the same time period [5]. Similarly, comparing firm performance of ERP adopters and ERP nonadopters, [4] reveal that ERP adopters are constantly higher in performance across a wide variety of measures than nonadopters of ERP systems.

In order for information technology to improve performance, previous studies have indicated that a time lag is crucial. Therefore, some research explores the changes in firm performance from 1 year before to 3 years after ERP implementation and find no significant improvement associated with residual income or the ratio of selling, general, and administrative expenses in each of the 3 years after ERP implementation. However, a significant improvement associated with a decline in the ration of cost of goods sold to revenues was found 3 years after the ERP implementation and the ratio of employees to revenues for each of the 3 years after ERP implementation [14]. In addition, [8] found that the adoption of ERP systems leads to sustained operational efficiencies, improved overall liquidity and increased profitability 2 years after the ERP implementation. The ERP implementation impacts operational performance, at both, the modular and the systemic levels. Apropos, as the implementation status of the ERP system 
(module) increases, operational performance is significantly influenced [7].

Some research considers and studies the role of management accounting practices in the mediated relationship influences ERP systems against the performance of the firm. Therefore, accounting techniques used after the ERP systems implementation can affect the performance of the firm amounting to $68.5 \%$ [18]. Many firms started to use ERP systems in order to accomplish better business performance, and according to [13] IIS positive and significant influence the use of advanced managerial accounting techniques in order to provide managers with high-quality information.

As important critique of previous research here we can point out the fact that the existing literature mainly focuses on ERP without detailed insight into other related analytical applications and IIS features. Transaction oriented IIS has very limited effects on decision making process in comparison with more analytical oriented IIS, what in turn may be reflected in firm performance. Accordingly, we predict to find influence of IIS features (analytical capabilities, scope, age and implementation quality) over firm financial performance.

\section{Methodology and data}

\subsection{Sample}

Data required for empirical modelling of IIS implementation characteristics on firm profitability was collected during the 2018 with extensive online questionnaire. Questionnaire was sent to randomly selected sample of 500 firms from Croatia. Among 133 filled questionnaires (all IIS adopters), 83 was filled with all data required for this type of research, giving an appropriate response rate $(\mathrm{RR})$ of $16.6 \%$. Table 1 shows some basic statistics about the sampled firms.

\begin{tabular}{|l|rr|}
\hline Type of firm & $\mathrm{N}$ & $\%$ \\
\hline \hline Joint-stock firm & 33 & 39.8 \\
Limited liability firm & 49 & 59.0 \\
Other & 1 & 1.2 \\
Total & 83 & 100 \\
\hline Main activity & $\mathrm{N}$ & $\%$ \\
\hline \hline Agriculture, forestry and fishing & 3 & 3.6 \\
Mining and quarrying & 1 & 1.2 \\
Manufacturing & 31 & 37.3 \\
Supply with electric energy, gas, steam and climatisation & 1 & 1.2 \\
Water supply, sewerage and waste management & 4 & 4.8 \\
Construction & 2 & 2.4 \\
Retail and wholesale trade, repair of motor vehicles and motorcycles & 14 & 16.9 \\
Transporting and storage activities & 8 & 9.6 \\
Accommodation and food service & 10 & 12.0 \\
Information and communication & 2 & 2.4 \\
Real estate activities & 1 & 1.2 \\
Professional, scientific and technical activities & 2 & 2.4 \\
Administrative and support service activities & 3 & 3.6 \\
Other service activities & 1 & 1.2 \\
Total & 83 & 100 \\
\hline
\end{tabular}

Table 1: Summary statistics on responding firms 
Sample size and response rate was similar in comparison with previous research from other countries like India, $\mathrm{N}=154$ [2], Australia, $\mathrm{N}=102, \mathrm{RR}=5.7 \%$ [19], Finland, $\mathrm{N}=70, \mathrm{RR}=9.6 \%$ [6], China, $\mathrm{N}=65, \mathrm{RR}=15 \%$ [1], Lebanon, $\mathrm{N}=50$ [16]. Designed questionnaire incorporated questions that were required for measurement of firm profitability and implemented IIS characteristics (scope, analytical capabilities, age and implementation quality).

Collected data indicated that majority of respondents were the large firms (55.4\%), while the lowest number of respondents were micro firms (3.6\%). Considering ownership type, the most of responding firms had private owner $(72.3 \%)$, while $12 \%$ of responding firms are stateowned. Further, majority of responding firms were limited liability firms (59\%) and $39.8 \%$ are joint-stock firms. Industry classification (Croatian NKD) reveals that $37.3 \%$ of respondents were from manufacturing industry, $16.9 \%$ were from retail and wholesale trade, while $12 \%$ were from accommodation and food service industry.

\subsection{Variables}

Financial performance metrics represent one of the most important aspects of measuring of firm performance [7], therefore in modelling we incorporated financial performance as the most commonly used business performance indicator. Firm financial performance can be measured by different indicators (ROA, ROE, ROS, etc.) but we have decided to use ROA since it represents firm profitability irrespective of firm financial structure, i.e. capital/debt structure. Namely, since our data set incorporates data for large, medium, small and micro firms it is expected that sampled firms do not have the same financial structure and interest expenses. In order to avoid different profitability level caused by financial structure the best solution was usage of profitability indicator that is not affected by sources of financing. ROA variable was calculated as ratio of earnings before interest and tax (EBIT) and assets on the basis of financial reports from 2018.

For IIS, we follow [15] approach and describe IIS as a set of ERP modules and specialized applications outside of ERP systems. In order to explore the relation among implemented IIS and financial performance of firm we have used most important IIS features (IIS analytical capabilities, IIS age, IIS scope and IIS implementation quality), while controlling for some important firm characteristics. Variables used in modelling are in Table 2.

\begin{tabular}{|l|ll|}
\hline Acronym & Variable & Measurement \\
\hline \hline ROA & Return on assets & EBIT/Assets (2018) \\
IIS_AC & IIS analytical capabilities & Construct measured by nine items on Likert scale \\
IIS_S & IIS scope & Number of IIS modules \\
IIS_A & IIS age & Number of years from initial IIS installation \\
IIS_IQ & IIS implementation quality & Value based on Likert scale \\
\hline
\end{tabular}

Table 2: Variables description

IIS_A was measured in years, which represent number of years that firm uses IIS. IIS_IQ was measured on the basis of questionnaire and expert opinions. IIS_AC variable represents construct based on nine items (Table 3). Estimated Cronbach's Alpha was high (0.913) confirming internal consistency of designed research instrument. Sampling adequacy was evaluated on the basis of Kaiser-Meyer-Olkin (KMO). For the IIS_AC construct KMO value was more than 0.6 indicating sampling adequacy. Bartlett's test of sphericity resulted with value less than $5 \%$, revealing that there might be a significant relationship among items. Factor analysis for IIS_AC constructs, extracted one component, with initial eigenvalue higher than 1 . Variance explained by such extracted component reached $57.3 \%$. 


\begin{tabular}{|l|c|}
\hline Item & Principal component loading \\
\hline \hline IIS_SIMULATION & 0.811 \\
IIS_DMINING & 0.806 \\
IIS_FORCAST & 0.798 \\
IIS_PR_REALT & 0.793 \\
IIS_KFI & 0.757 \\
IIS_DASHBO & 0.754 \\
IIS_KNFI & 0.747 \\
IIS_KPI_SEGM & 0.722 \\
IIS_ABC & 0.719 \\
\hline
\end{tabular}

Table 3: IIS analytical capabilities items

Alongside with IIS features that were focal point of this study we have decided to control for main firm characteristic that may also influence financial performance. Accordingly, we have decided to incorporate two control variables, firm size (SIZE) and perceived environment uncertainty (PEU). SIZE was measured in four categories (large, medium, small or micro firm), according to current EU regulation. PEU represents construct, which consists of eight items measured by five points Likert scale. Estimated Cronbach's Alpha was 0.804 indicating instrument reliability. In the case of PEU construct KMO value was 0.6, confirming sampling adequacy. Bartlett's test of sphericity had desired value less than 5\%. Factor analysis for PEU constructs, extracted one component, with initial eigenvalue higher than 1. Variance explained by such extracted component reached $59 \%$.

\subsection{Measurement model}

Most previous research used performance of the firm as the regressand variable in modelling [7] thus this study sheds light on the question of how IIS implementation contributes to the financial business performance. Therefore, we examine the influence of IIS features on financial performance of firm.

Figure 1 shows the theoretical model employed in this research. According to our theoretical model we expect that more analytical oriented IIS will result with improved decision making and better financial performance. Also, IIS age and implementation quality may contribute to improvement of business processes and financial performance. IIS scope can be related with IIS investment and area of coverage of business processes. While broader scope IIS may cover large set of business operations allowing better management, firms should be careful with overall cost of IIS investment and related benefits. In other words, there should be balancing among IIS investments and expected financial benefits.

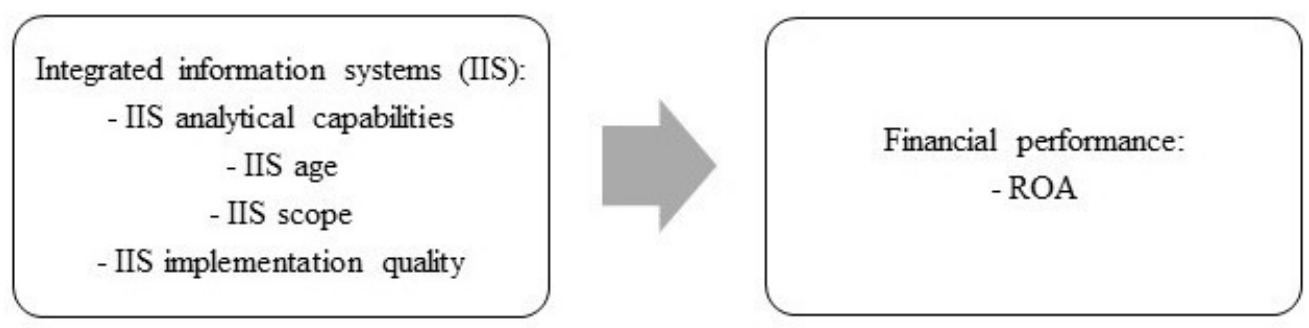

Figure 1: Theoretical model 


\section{Results}

Influence of IIS characteristics on firm performance was evaluated with application of multiple regression analysis. As dependent variable in the model we have decided to use ROA, while IIS scope, IIS analytical capabilities, IIS age and IIS implementation quality were used as independent variables. Regression model was estimated with application of SPSS 23 software, while results are presented in Table 4. Calculated F-ratio of 2.581 and resulting significance of 0.044 indicated that model has good overall fit. Estimated model has shown moderate explanatory power since R2 was $12.1 \%$. Such finding was not surprising since firm profitability might be influenced by some other variables, which were not included into modelling. Multicolinearity among independents was tested with Variance Inflation Factors - VIFs. All calculated VIFs were lower than 5 indicating that there was no evidence of significant multicollinearity problem. Also, Durbin-Watson test resulted with value 2.2 indicating that there is no problem in autocorrelation of residuals.

\begin{tabular}{|l|cccc|}
\hline Variable & Coefficient & Standard Error & t-statistic & p-value \\
\hline \hline Constant & 16.922 & 6.544 & 2.5858 & 0.0116 \\
IIS_AC & 2.7310 & 0.979 & 2.7910 & 0.007 \\
IIS_S & -0.540 & 0.271 & -1.996 & 0.050 \\
IIS_A & -0.146 & 0.147 & -0.991 & 0.325 \\
IIS_IQ & -1.382 & 1.434 & -0.964 & 0.338 \\
\hline
\end{tabular}

Table 4: Regression model results

According to the estimated regression model, it was confirmed that IIS analytical capabilities were positively related with firm profitability. Namely, positive sign of IIS_AC variable, indicated that an increase in analytical capabilities of IIS results with higher firm performance measured by ROA. IIS scope variable was negatively related with firm performance, while coefficient was significant at $5 \%$ level. However, other two IIS characteristics (IIS_A and IIS_IQ) were unrelated with firm performance. In addition, two control variables, SIZE and PEU, were statistically insignificant and therefore control variables were excluded from the final regression.

\section{Discussion}

Along with global large-scale implementation of IIS academia has started with examination about the effects of IIS implementation on firm. This research is focusing on exploration of expected positive consequence of IIS implementation over increased financial performance, i.e. we expect that some of IIS features will positively influence firm performance. We observe only financial performance indicators, represented by return on assets (ROA) since it represents firm profitability irrespective of firm financial structure. ROA variable was calculated on the basis of financial reports from 2018 as ratio of earnings before interest and tax (EBIT) and assets. In order to explore the influence of IIS on firm financial performance we have used most important IIS features that is IIS analytical capabilities, IIS age, IIS scope and IIS implementation quality, while controlling some important firm characteristics, firm size (SIZE) and perceived environment uncertainty (PEU). In line with our theoretical expectations and findings from similar previous research, this study confirmed that IIS characteristics affect firm financial performance. Namely, IIS analytical capabilities are statistically positively related with ROA. Such finding indicated that firms, which have invested in IIS with higher analytical capabilities (forecasting, data mining, planning, etc.), achieve higher profitability. Higher level of analytical capabilities probably results with timely prepared high-quality decision-making information, assuring good decision-making processes. 
Contrary to that, IIS scope seems to have negative impact on ROA, what indicates that firms must be rational with IIS investments. Investing in large set of IIS modules might be a very expensive decision and therefore firms should focus IIS development on the most important modules, which will result with the largest benefits.

\subsection{Implications for theory and practice}

This research contributes to the level of scientific research in theory and practice. As a theoretical contribution, in this research we use broad description of IIS, which comprises ERP and additional specialized applications, ie stand-alone applications (outside ERP), connected to a single database, which support individual processes/activities (consolidation, budgeting, customer relations, etc.). Moreover, we established several IIS features that may have a significant influence on the firm financial performance which results with improved measurement of IIS variable and with more reliable findings. Although IIS are expected to result in a better business performance, empirical evidence is unclear [3] so, in order to fill the gap, we examine the influence of IIS on the firm financial performance. This study represents one of the very rare studies that explores the influence of IIS on firm financial performance in Croatia and in South East European (SEE) countries. Findings from the study are useful for both firms and IIS vendors. Firms and IIS vendors should be careful in IIS design phase, taking into account that IIS design incorporates appropriate analytical capabilities required by business processes. On the other side, scope of selected IIS modules should be rational in order to avoid unnecessary IIS investment costs.

\subsection{Limitations of the study}

The results should be interpreted with caution given the limitations of the research. Although research sample incorporated data collected from 83 firms and response rate was at satisfactorily level, some future research should be based on larger sample. Larger sample would enable application of more sophisticated methodologies. Thus for example, use of structural equation modelling might reveal some additional direct/indirect relationships among variables. Furthermore, data required for this research was collected at a single point of time although previous studies have indicated that a time lag is crucial. Therefore, some future research should investigate the changes in firm performance at different points in time with regard to the introduction of IIS. Previous research [12] suggests that a number of the variables (top management support, organizational complexities, employee perceptions, etc.) influenced the implementation of IIS and therefore the performance of an organization so this is one more suggestion for future research.

\section{Conclusion}

Contemporary business environment requires of firms dealing with large amount of quantitative and qualitative information. In order to timely and efficiently deal with such challenge many firms employ IIS, which include ERP and specialized BoB applications. Although in initial stage of IIS implementation investment are often large, in later implementation stages it is also necessary to invest time and money in employee education and IIS adjustments. All these investments related with IIS are undertaken aiming to improve business processes, decisionmaking procedures and consequently to enhance firm financial performance. In this research, a theoretical model was developed and a survey instrument constructed to gather data for testing the assumption that more analytical oriented IIS will result with improved decision making and better firm financial performance. Our findings suggest that an increase in analytical capabilities of IIS results with higher firm performance measured by ROA. IIS scope variable was negatively 
related with firm performance, while IIS age and IIS implementation quality were unrelated with firm performance. In addition, two control variables, firm size and perceived environment, were statistically insignificant. We hope future research extends our line of thinking and considers the use of more sophisticated methodologies, taking into account a time lag.

\section{Acknowledgements}

We would like to thank reviewers for taking the time and effort necessary to review the paper and we sincerely appreciate all valuable comments and suggestions, which helped us to improve the quality of the article.

\section{References}

[1] Chen, S., Elbashir, M. Z., Peng, X. and Zhu, D. X. (2016). The effect of ERP systems competences on business process and organizational performance. International Journal of Management Theory and Practices, 17(1), 5-35. http://www.myacme.org/ijmtp/IJMTPV17N1/IJMTP16090_Zhu.pdf

[2] Gupta, S., Kumar, S., Kumar Singh, S., Foropon, C. and Chandra, C. (2018). Role of cloud ERP on the performance of an organization: Contingent resource-based view perspective. The International Journal of Logistics Management, 29(2), 659-675. doi: 10.1108/ijlm-07-2017-0192

[3] Hendricks, K. B., Singhal, V. R. and Stratman, J. K. (2007). The impact of enterprise systems on corporate performance: A study of ERP, SCM, and CRM system implementations. Journal of Operations Management, 25(1), 65-82. doi: 10.1016/j.jom.2006.02.002

[4] Hitt, L. M., Wu, D. J. and Zhou, X. (2002). Investment in enterprise resource planning: business impact and productivity measures. Journal of Management Information Systems, 19(1), 71-98. doi: 10.1080/07421222.2002.11045716

[5] Hunton, J. E., Lippincott, B. and Reck, J. L. (2003). Enterprise resource planning systems: Comparing firm performance of adopters and non-adopters. International Journal of Accounting Information Systems, 4(3), 165-184. doi: 10.1016/s1467-0895(03)00008-3

[6] Kallunki, J. P., Laitinen, E. K. and Silvola, H. (2011). Impact of enterprise resource planning systems on management control systems and firm performance. International Journal of Accounting Information Systems, 12(1), 20-39. doi: 10.1016/j.accinf.2010.02.001

[7] Madapusi, A. and D'Souza, D. (2012). The influence of ERP system implementation on the operational performance of an organization. International Journal of Information Management, 32(1), 24-34. doi: 10.1016/j.ijinfomgt.2011.06.004

[8] Matolcsy, Z., Booth, P. and Wieder, B. (2005). The economic benefits of enterprise resource planning systems: Some empirical evidence. Accounting and Finance, 45(3), 439-456. doi: 10.1111/j.1467-629x.2005.00149.x

[9] Milanović Glavan, Lj. (2014). Process information technology in Croatian companies. Collected Papers of Šibenik College, 3-4, 35-48. https://hrcak.srce.hr/131349

[10] Nicolaou, A. I. (2004). Firm performance effects in relation to the implementation and use of enterprise resource planning systems. Journal of Information Systems, 18(2), 79-105. doi: $10.2308 /$ jis.2004.18.2.111

[11] Nicolaou, A. I. and Bhattacharya, S. (2008). Sustainability of ERPS performance outcomes: The role of post-implementation review quality. International Journal of Accounting Information Systems, 9(1), 43-60. doi: 10.1016/j.accinf.2007.07.003

[12] Njihia, E. and Mwirigi, F. M. (2014). The effects of enterprise resource planning systems on firm's performance: A survey of commercial ranks in Kenya. International Journal of Business and Commerce, 3(8), 120-129. https://www.ijbcnet.com/3-8/IJBC-14-3812.pdf

[13] Pervan, I. and Dropulić, I. (2019). The impact of integrated information systems on management accounting: Case of Croatia. Management, 24(1), 21-38. doi: 10.30924/mjcmi.24.1.2

[14] Poston, R. and Grabski, S. (2001). Financial impacts of enterprise resource planning implementations. International Journal of Accounting Information Systems, 2(4), 271-294. doi: 10.1016/s1467-0895(01)00024-0 
[15] Rom, A. and Rohde, C. (2006). Enterprise resource planning systems, strategic management systems and management accounting. Journal of Enterprise Information Management, 19(1), 5066. doi: 10.1108/17410390610636878

[16] Saleh, T. and Thoumy, M. (2020). The impact of ERP systems on organizational performance in Lebanese wholesale engineering companies. International Journal of Services and Operations Management, 37(1), 1-X. doi: 10.1504/ijsom.2020.10018469

[17] Shen, Y. C., Chen, P. S. and Wang, C. H. (2016). A study of enterprise resource planning (ERP) system performance measurement using the quantitative balanced scorecard approach. Computers in Industry, 75, 127-139. doi: 10.1016/j.compind.2015.05.006

[18] Wajdi, F. (2018). The role of management accounting practices in the use of the mediate relation the quality of information and the quality of an ERP system on performance of companies in Indonesia manufacture. Akuntabilitas, 11(2), 257-280. doi: 10.15408/akt.v11i2.8640

[19] Wieder, B., Booth, P., Matolcsy, Z. P. and Ossimitz, M. L. (2006). The impact of ERP systems on firm and business process performance. Journal of Enterprise Information Management, 19(1), 13-29. doi: 10.1108/17410390610636850 